\title{
Factors Associated with Para-central Defect for Primary Open Angle Glaucoma in a Singaporean Chinese Population
}

Dr. Shyam Kumar Gupta ${ }^{1}$, Dr. Bhaskar Agarwal ${ }^{2 *}$

\author{
1 (MBBS, MS) Singapore Eye Research Institute, Singapore \\ ${ }^{2}$ Associate Professor, Department of Prosthodontics, King George's Medical University, Shah Mina Rd, Chowk, Lucknow, Uttar \\ Pradesh 226003, India
}

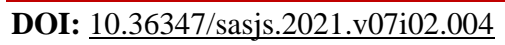

| Received: 21.01.2021 | Accepted: 04.02.2021 | Published: 06.02.2021

*Corresponding author: Dr. Bhaskar Agarwal

\begin{abstract}
Aim: To determine the factors associated with para-central defect for primary open angle glaucoma in a Singaporean Chinese population. Methods: In a retrospective case series of Singaporean Chinese primary Open Angle Glaucoma (POAG) cohort, we analyzed the pattern of visual field defect at the first time of presentation. Diagnosis was categorized as normal tension glaucoma (NTG) if untreated presenting diurnal intraocular pressure (IOP) was $\leq 21 \mathrm{~mm}$ $\mathrm{Hg}$ and high tension glaucoma (HTG) if IOP was $>21 \mathrm{~mm} \mathrm{Hg}$. Para central defect was defined as glaucomatous defect $(\mathrm{p}<0.5 \%)$ within $10^{\circ}$ of fixation in pattern deviation plot and all other glaucomatous defects were grouped as non-para central defects. Para central defect (PCD)was considered the dependent variable with age, gender, logmar visual acuity (Log VA), IOP, central corneal thickness (CCT), vertical cup disc ratio(VCDR), mean deviation (MD) value, diagnosis and co-morbid conditions (hypertension, diabetes, asthma, ischemic heart disease) at presentation were considered as independent variables for multivariate regression analysis. Results: Of the 887eyes of 887 POAG patients included, $146(16.45 \%)$ had PCD at presentation. Mean age was $62.37( \pm 9.9)$ years, males were $67.4 \%$, $673(75.8 \%)$ had HTG and 214(24.1\%) had NTG.PCD was significantly associated with lower presenting IOP $(\beta=-$ $0.051, p=0.002)$, NTG $(\beta=-0.672, p=0.001)$ and lower MD values $(\beta=0.077, p<0.001)$. Conclusion: Para-central visual field defects were associated with NTG, lower presenting IOP and less severe visual field defects at initial presentation.

Keywords: Para-central Defect, Primary Open Angle Glaucoma (POAG), Normal Tension Glaucoma (NTG), Intraocular Pressure (IOP).

Copyright (C) 2021 The Author(s): This is an open-access article distributed under the terms of the Creative Commons Attribution 4.0 International License (CC BY-NC 4.0) which permits unrestricted use, distribution, and reproduction in any medium for non-commercial use provided the original author and source are credited.
\end{abstract}

\section{INTRODUCTION}

Adult onset primary open angle glaucoma (POAG) is the leading cause of irreversible blindness worldwide. Visual field defects in glaucoma patients commonly occur in the periphery and gradually extend to central field. Some glaucoma patients might present with central field defect as para-central scotoma, denoting loss of the maculo papillary nerve fiber layer bundles. The patients with these defects may have a higher threat of visual acuity loss, reading difficulty and poor driving performance [1-3].

Para-central defects (PCD) have been described to occur more often in eyes with intraocular pressure (IOP) within the normal range (normal tension glaucoma) than high pressure open angle glaucoma $[4$, 5], even though some reports have been nonconfirmatory $[6,7]$. Visual loss morphology study has shown a significant difference in sensitivity between HTG and NTG [8]. In developed countries, patients with open angle glaucoma, more advanced visual field loss at presentation and advanced age have been found to be the risk factor for development of blindness [9].

Glaucoma patient with initial para-central scotoma are more likely to have vascular factors (hypotension, migraine, Raynaud's phenomenon and sleep apnea) than patients with initial peripheral defects [9]. A Caucasian cohort from United States and Australia have found association of p53 codon 72 PRO/PRO genotype with early visual field defects in POAG patients with PCD [11].

However, the glaucomatous visual field (VF) defects with para-central scotoma in previous studies included numerous types (open, closed and pigmentary) 
Shyam Kumar Gupta \& Bhaskar Agarwal., SAS J Surg, Feb, 2021; 7(2): 44-48

of glaucoma and only patients with early defects. Role of multiple chronic illnesses like diabetes mellitus, hypertension, ischemic heart disease and hypercholestremia in pathogenesis of open angle glaucoma associated with PCD is not studied.

Factors associated with PCD in comparison to glaucomatous defects of varying severity at the time of presentation was not clearly documented and no data on risk factors of PCD for Chinese population available so far. We therefore investigated risk factors associated with clinical characteristics of PCD in comparison to all other non-para central visual field defects at the time of presentation in a cohort of Singaporean Chinese POAG patients.

\section{METHOD}

The records of all the patients of established primary open angle glaucoma (POAG) enrolled in study a genetics study recruiting POAG patients were reviewed for this retrospective study.

Age, gender, logmar visual acuity (Log VA), IOP, Vertical cup disc ratio, Central corneal thickness (CCT), Mean deviation (MD) and Diagnosis high tension glaucoma (HTG) or Normal tension glaucoma (NTG) noted at the time of diagnosis in glaucoma clinic were retrieved from medical records. The diagnosis of POAG required the following criteria: presence of glaucomatous optic neuropathy (defined as loss of neuro retinal rim with a vertical cup: disc ratio of $>0.7$ or an inter-eye asymmetry of $>0.2$, and/ or notching attributable to glaucoma) with compatible visual field loss, open angles on gonioscopy, and absence of secondary causes of glaucomatous optic neuropathy. POAG patients with a mean IOP without treatment that is consistently $\leq 21 \mathrm{~mm} \mathrm{Hg}$ on diurnal testing using hourly non-contact air-puff tonometry (between 8 am to $5 \mathrm{pm}$ ) are classified as having NTG, whereas those with a mean IOP without treatment that is consistently $>21$ $\mathrm{mm} \mathrm{Hg}$ are classified as having high-tension glaucoma (HTG). The prevalence of systemic factors, such as hypertension, diabetes, ischemic heart disease, asthma, hypercholesterolemia was also noted to find the systemic factors of PCD.

\section{Inclusion Criteria}

Only those patients who have the records of reliable visual fields within one year of initial presentation were considered for this study.

\section{Statistical Analysis \\ Commercially available Statistical software (SPSS version 21) was used for analysis. Age, log VA,}

IOP, CCT, VCDR, MD value, diagnosis and systemic co-morbid conditions at the time of diagnosis were compared using independent t-test or Mann-Whitney U test between PCD and non PCD groups. Gender and type of POAG, high tension glaucoma (HTG) or normal tension glaucoma (NTG) were compared by using the chi-square test or Fisher's extract test. The relation with all the variables and PCD were assessed by regression methods. All the outcome variables firstly analyzed by univariate logistic regression and significant variables were analyzed again by multivariate logistic regression. $\mathrm{P}<0.05$ was considered significant.

\section{RESULTS}

Data of nine hundred seventy eight eyes of 978 patient's, with a diagnosis of HTG or NTG was available at time of the study. Of these, 91 eyes were excluded because of low visual field test reliability within one year of presentation. Out of 887 reliable visual fields, $146(16.45 \%)$ patients presented with PCD and $741(83.54 \%)$ patients presented with non-para central visual field defects in glaucoma clinic. There was no significant difference between 2 groups (PCD vs. non $\mathrm{PCD})$ in age $(62.05+10.15$ yrs. vs. $62.44+9.9$ yrs; $\mathrm{P}=0.69)$, male - female ratio $(\mathrm{P}=0.7)$, Log VA $(0.27+10.15$ vs. $0.33+0.5 ; \mathrm{P}=0.687), \mathrm{CCT}(0.538+0.035$ $\mathrm{mm}$ vs. $0.541+0.035 \mathrm{~mm} ; \mathrm{P}=0.388)$ and $\mathrm{CD}$ ratio $(0.79+0.12$ vs. $0.78+0.15 ; \mathrm{P}=0.652)$. Systemic diseases like hypertension, diabetes mellitus, hypercholestrolemia, asthma, and ischemic heart disease were not significantly different between these groups $(\mathrm{P}>0.6)$. However, PCD group had more NTG patients $(26.2 \%$ vs $13.4 \%, \mathrm{P}<0.001)$, lower untreated presenting IOP $(21.77+5.7$ vs. $24.80+7.3 ; \mathrm{P}<0.001)$ and less severe MD values (-8.09+4.9 vs. - 13.69+9.6; $\mathrm{P}<0.001)$ compared with HTG group (Table-1).

Table-2 shows the results of univariate regression analysis with $\mathrm{PCD}$ as dependent variable. Factors significantly associated with PCD were diagnosis $($ Odds $=0.436)$, IOP (Odds for per unit increase $=0.932$ ) and $\mathrm{MD}$ values at presentation (Odds for per unit increase $=1.09$ ). PCD was not associated with age, visual acuity, $\mathrm{CCT}$ and $\mathrm{CD}$ ratio.

Table-3 shows the results of multivariate regression analysis with PCD as dependent variable and age, gender, IOP, MD values and diagnosis as independent variables. PCD was significantly associated with lower presenting IOP $(\beta=-0.051$, $\mathrm{p}=0.002)$, NTG $(\beta=-0.672, \mathrm{p}=0.001)$ and lower MD values $(\beta=0.077, \mathrm{p}<0.001)$. 
Shyam Kumar Gupta \& Bhaskar Agarwal., SAS J Surg, Feb, 2021; 7(2): 44-48

Table-1: Demographics and comparisons between para-central defect (PCD) and non-para central defect (NonPCD) groups

\begin{tabular}{|c|c|c|c|c|c|}
\hline & \multicolumn{2}{|c|}{ PCD group $(n=146)$} & \multicolumn{2}{|c|}{ Non PCD group $(n=741)$} & \multirow[t]{2}{*}{ P value } \\
\hline & $\mathbf{N}$ & mean \pm SD & $\mathbf{N}$ & mean \pm SD & \\
\hline Age (years) $n=887$ & 146 & $62.05(+10.15)$ & 741 & $62.44(+9.9)$ & 0.69 \\
\hline Male n=596 & 96 & $(16.1 \%)$ & 500 & $(83.9 \%)$ & \multirow[t]{2}{*}{0.7} \\
\hline Female $n=291$ & 50 & $(17.2 \%)$ & 241 & $(82.8 \%)$ & \\
\hline Log VA n $=879$ & 146 & $.27(+10.15)$ & 733 & $0.33(+0.5)$ & 0.687 \\
\hline $\mathrm{IOP}(\mathrm{mmHg}) \mathrm{n}=887$ & 146 & $21.77(+5.7)$ & 741 & $24.80(+7.3)$ & $<0.001$ \\
\hline $\mathrm{CCT}(\mathrm{mm}) \mathrm{n}=680$ & 123 & $0.538(+0.035)$ & 557 & $0.541(+0.035)$ & 0.388 \\
\hline VCDR $n=886$ & 145 & $0.79(+0.12)$ & 741 & $0.78(+0.15)$ & 0.652 \\
\hline MD value $(\mathrm{dB}) \mathrm{n}=887$ & 146 & $-8.09(+4.9)$ & 741 & $-13.69(+9.6)$ & $<0.001$ \\
\hline HTG $n=673$ & 90 & $13.4 \%$ & 583 & $86.6 \%$ & \multirow[t]{2}{*}{$<0.001$} \\
\hline NTG $n=214$ & 56 & $26.2 \%$ & 158 & $73.8 \%$ & \\
\hline Hypertension $n=396$ & 55 & $13.9 \%$ & 341 & $8.6 \%$ & .069 \\
\hline
\end{tabular}

\begin{tabular}{|l|l|l|l|l|l|}
\hline Diabetes Mellitus $\mathrm{n}=218$ & 35 & $16.1 \%$ & 183 & $83.9 \%$ & 0.916 \\
\hline Hypercholestremia $\mathrm{n}=177$ & 31 & $17.5 \%$ & 146 & $82.5 \%$ & 0.734 \\
\hline Ischemic Heart Disease (IHD) $\mathrm{n}=50$ & 7 & $14 \%$ & 43 & $86 \%$ & 0.7 \\
\hline Asthma $\mathrm{n}=15$ & 2 & $13.3 \%$ & 13 & $86.7 \%$ & 1.0 \\
\hline
\end{tabular}

SD - Standard deviation; Log VA - logmar visual acuity; IOP - intraocular pressure; CCT - central corneal thickness; VCDR - vertical cup disc ratio; MD - mean deviation; HTG - high tension glaucoma; NTG - normal tension glaucoma; $\mathrm{dB}=$ decibel; $\mathrm{mm}=$ millimeter.

Table-2: Results of univarite regression model evaluating the factors associated with para-central defect (PCD)

\begin{tabular}{|l|l|l|l|}
\hline Factors & Beta & OR(95\% CI) & P value \\
\hline Age $($ yrs.) & -0.004 & $0.996(0.98-1.01)$ & 0.664 \\
\hline Gender & -0.077 & $0.925(0.64-1.35)$ & 0.685 \\
\hline Log VA & -0.321 & $0.725(0.46-1.14)$ & 0.164 \\
\hline IOP $(\mathrm{mmHg})$ & -0.071 & $0.932(0.90-0.96)$ & $<0.001$ \\
\hline CCT $(\mathrm{mm})$ & -2.97 & $0.051(0.00-15.36)$ & 0.307 \\
\hline CD ratio & 0.378 & $1.46(0.414-5.14)$ & 0.557 \\
\hline MD Value(dB) & 0.083 & $1.09(1.06-1.12)$ & $<0.001$ \\
\hline Diagnosis ${ }^{\#}$ & -0.831 & $0.436(0.30-0.64)$ & $<0.001$ \\
\hline
\end{tabular}

SD - Standard deviation; Log VA - log mar visual acuity; IOP - intraocular pressure; CCT - central corneal thickness; VCDR - vertical cup disc ratio; MD - mean deviation; HTG - high tension glaucoma; NTG - normal tension glaucoma; $\mathrm{dB}=$ decibel; $\mathrm{mm}=$ millimeter.

* At the time of presentation in Glaucoma Clinic; \# reference NTG

Table-3: Results of multivariate regression model evaluating the factors associated with para-central defect (PCD)

\begin{tabular}{|l|l|l|}
\hline Factors $^{*}$ & Beta & P value \\
\hline Age(years) & 0.006 & 1.006 \\
\hline Gender & 0.150 & 0.449 \\
\hline IOP(mmHg) & -0.051 & 0.002 \\
\hline MD Value(dB) & 0.077 & $<0.001$ \\
\hline Diagnosis ${ }^{\#}$ & -0.672 & 0.001 \\
\hline
\end{tabular}

IOP - Intraocular pressure; MD - mean deviation; $\mathrm{dB}$ - decibels;

* At the time of presentation in Glaucoma Clinic; \# reference NTG

\section{DISCUSSION}

We classified patients with POAG according to their pattern of VF loss at presentation and compared the associated factors. PCD group had a significant lower untreated IOP and initial MD value (less severe
VF loss) and higher prevalence of NTG. Systemic factors like hypertension, diabetes, asthma, hypercholestrolemia and ischemic heart disease were not associated with PCD in this study. Therefore, our results support that the development of PCD may be associated with IOP independent factors. By considering the structure functional relationship in previously reported studies [12-16], it may be presumed that, in the early stage of glaucoma, IOP independent factors may preferentially damage the neuroretinal rim or retinal nerve fiber layer closer to the papilla-macular bundle in comparison with elevated IOP.

IOP is one of the most crucial known risk factors for glaucomatous damage; glaucoma has been divided into NTG and HTG on the basis of untreated IOP. Studies on the visual field defects in NTG eyes have shown scotoma closure to fixation [5]. Few study results have shown no difference in para-central visual field defects between NTG and HTG patients [6, 7, 17], 
Shyam Kumar Gupta \& Bhaskar Agarwal., SAS J Surg, Feb, 2021; 7(2): 44-48

this may be due to smaller sample size to compare the para-central defects. Large sample size of our study could have substantiated the association of PCD with NTG. The association of lower presenting IOP seems independently associated with PCD in the multivariate regression analysis apart from the association of NTG (which is based on a definition of lower IOP) is an interesting finding with this it may point to a strong IOP independent association for this pattern of defects.

One of the studies comparing parafoveal scotoma and nasal step at diagnosis has shown no difference in severity of visual field loss [10]. There was paucity of data to show association of PCD with severity of visual field loss. Our study has shown that PCD is associated with less severe visual field loss [OR 1.09(1.06-1.12); $\mathrm{p}<0.001]$. Although the PCD lies closer to fixation, this study also showed that at presentation PCD did not affect usual acuity of patients significantly worse than HTG patients. Future prospective studies are needed to know the progression of these defects and their role in glaucomatous blindness.

Studies have shown CCT is not an influencing factor for glaucoma in Chinese population [18, 19]. Our study found no difference in CCT in PCD and non PCD patients. One study has shown more association of vascular disease with PCD [10]. Our study has shown that PCD is not associated with chronic non-vascular systemic diseases. To know more relevant associations of various factors associated with PCD, we included all patterns of VF loss. Majority of the studies on PCD have enrolled only mild field defects in comparison, while we included all categories of visual field defects to provide pragmatic analysis of the associations.

Limitations of the current study include its retrospective design. Prevalence of systemic risk factors was on the basis of records availability in our glaucoma clinic case sheets, which may be limited by reliability and accuracy. We did not find sufficient information on disc hemorrhage records on initial visit, which could have given valuable information regarding a vascular pathological process.

\section{CONCLUSION}

PCD in patients with POAG in Singaporean Chinese population was associated with NTG, lower untreated presenting IOP and less severe visual field defects. Chronic systemic diseases like hypertension, diabetes and ischemic heart diseases were not significantly associated with PCD in our study. Further studies are needed to elucidate the relationship between PCD and the VF progression in relation to visual disability.

\section{REFERENCE}

1. Kolker AE. Visual prognosis in advanced glaucoma: a comparison of medical and surgical therapy for retention of vision in 101 eyes with advanced glaucoma. Trans Am Ophthalmol Soc. 1977; 75:539 -55.

2. Fujita K, Yasuda N, Oda K, Yuzawa M. Reading performance in patients with central visual field disturbance due to glaucoma. Nippon Ganka Gakkai Zasshi. 2006; 110:914-8.

3. Coeckelbergh TR, Brouwer WH, Cornelissen FW, Van Wolffelaar P, Kooijman AC. The effect of visual field defects on driving performance: a driving simulator study. Archives of ophthalmology. 2002 Nov 1;120(11):1509-16.

4. Hitchings RA, Anderton SA. A comparative study of visual field defects seen in patients with lowtension glaucoma and chronic simple glaucoma. $\mathrm{Br}$ J Ophthalmol. 1983; 67:818-21.

5. Caprioli J, Spaeth GL. Comparison of visual field defects inthe low-tension glaucomas with those in the high-tension glaucomas. Am J Ophthalmol. 1984; 97:730 -7.

6. Motolko M, Drance SM, Douglas GR. Visual field defects in low-tension glaucoma: comparison of defects in low-tension glaucoma and chronic open angle glaucoma. Arch Ophthalmol. 1982; 100:1074 -7 .

7. King D, Drance SM, Douglas G, Schulzer M, Wijsman K. Comparison of visual field defects in normal-tension glaucoma and high-tension glaucoma. American journal of ophthalmology. 1986 Feb 1;101(2):204-7.

8. Iester M, De Feo F, Douglas GR. Visual field loss morphology in high- and normal-tension glaucoma. J Ophthalmol. 2012; 2012:327326.

9. Chen PP. Risk and risk factors for blindness from glaucoma. Curr Opin Ophthalmol. 2004; 15(2):107-11.

10. Park SC, De Moraes CG, Teng CC, Liebmann JM, Ritch R. Initial Parafoveal Versus Peripheral Scotomas in Glaucoma: Risk Factors and Visual Field Characteristics. Ophthalmology. 2011; 118:1782-1789.

11. Wiggs JL, Hewitt AW, Fan BJ, Wang DY, Sena DR, O'Brien C, Realini A, Craig JE, Dimasi DP, Mackey DA, Haines JL. The p53 codon 72 PRO/PRO genotype may be associated with initial central visual field defects in caucasians with primary open angle glaucoma. PLoS One. 2012 Sep 26;7(9):e45613.

12. Garway-Heath DF, Poinoosawmy D, Fitzke FW, Hitchings RA. Mapping the visual field to the optic disc in normal tension glaucoma eyes. Ophthalmology. 2000; 107:1809-15.

13. Ferreras A, Pablo LE, Garway-Heath DF, Fogagnolo P, García-Feijoo J. Mapping standard automated perimetry to the peripapillary retinal nerve fiber layer in glaucoma. Investigative ophthalmology \& visual science. 2008 Jul $1 ; 49(7): 3018-25$.

14. Kanamori A, Naka M, Nagai-Kusuhara A, Yamada Y, Nakamura M, Negi A. Regional relationship 
between retinal nerve fiber layer thickness and corresponding visual field sensitivity in glaucomatous eyes. Archives of ophthalmology. 2008 Nov 10;126(11):1500-6.

15. Horn FK, Mardin CY, Laemmer R, Baleanu D, Juenemann AM, Kruse FE, Tornow RP. Correlation between local glaucomatous visual field defects and loss of nerve fiber layer thickness measured with polarimetry and spectral domain OCT. Investigative ophthalmology \& visual science. 2009 May 1;50(5):1971-7.

16. Gardiner SK, Johnson CA, Cioffi GA. Evaluation of the structure-function relationship in glaucoma. Invest Ophthalmol Vis Sci. 2005; 46:3712-7.

17. Zeiter JH, Shin DH, Juzych MS, Jarvi TS, Spoor
TC, Zwas F. Visual field defects in patients with normal-tension glaucoma and patients with hightension glaucoma. Am J Ophthalmol. 1992; 114(6):758-63.

18. Day AC, Machin D, Aung T, Gazzard G, Husain R, Chew PT, Khaw PT, Seah SK, Foster PJ. Central corneal thickness and glaucoma in East Asian people. Invest Ophthalmol Vis Sci. 2011; 52(11):8407-12.

19. Wang D, Huang W, Li Y, Zheng Y, Foster PJ, Congdon $\mathrm{N}, \mathrm{He} \mathrm{M}$. Intraocularpressure, central corneal thickness, and glaucoma in chinese adults: the liwaneye study. Am J Ophthalmol. 2011; 152(3):454-462. 